\title{
Second Degree Perineal Laceration
}

National Cancer Institute

\section{Source}

National Cancer Institute. Second Degree Perineal Laceration. NCI Thesaurus. Code C114105.

Injury to perineum involving perineal muscles but not involving anal sphincter.

(reVITALize) 